\title{
Bilateral Facial Nerve Palsy following Head Injury: A Report of Two Uncommon Cases
}

\author{
Humam Nisar Tanki ${ }^{1}$ Shafeeq Alam Syed ${ }^{1}$ Sobiya Bilal ${ }^{1} \quad$ Nazish Aslam Chisti ${ }^{1} \quad$ Afzal Wani ${ }^{1} \quad$ Javeid \\ Sheikh ${ }^{1} \quad$ Qawnain Kirmani Syed ${ }^{1} \quad$ Umar Bachh $^{1} \quad$ Zia Ul Haque ${ }^{2}$
}

\author{
${ }^{1}$ Department of Neurosurgery, Super Specialty Hospital, \\ Government Medical College, Srinagar, Jammu and Kashmir, India \\ ${ }^{2}$ Department of Radiodiagnosis, Government Medical College, \\ Srinagar, Jammu and Kashmir, India
}

Address for correspondence Humam Nisar Tanki, MCh, Department of Neurosurgery, Super Specialty Hospital, Government Medical College, Srinagar, Jammu and Kashmir,190010, India (e-mail: humamtanki@yahoo.co.in).

Indian J Neurosurg:2020;9:183-185

\begin{abstract}
Keywords

- bilateral facial nerve palsy

- temporal bone fracture

- House and Brackmann

Bilateral facial nerve palsy (FNP) following head injury without any brain parenchymal injury or brain stem injury is quite an uncommon presentation. We came across two baffling cases of head trauma in which the patients developed simultaneous bilateral lower motor FNPs without any significant findings in initial brain scans which would suggest the pathophysiology for such a condition. Both the cases were found to be having longitudinal fractures of the temporal bone leading to injury of the facial nerves bilaterally. After conservative management, both the cases showed appreciable neurological improvement on follow-up. Hence, although bilateral FNP can be a diagnostic dilemma, it is quite possible to precisely localize the site of injury and successfully treat it.
\end{abstract}

\section{Introduction}

Post head injury cranial nerve dysfunction is not commonly encountered. Although facial nerve palsy (FNP) following trauma is seen often, but bilateral facial nerve palsy is very rarely seen. In literature, incidence of bilateral FNP is exceedingly rare, representing less than $2 \%$ of all facial palsy cases. ${ }^{1}$ Bilateral FNP has comparative incidence of only 1 in 5,000,000.,3 We present two patients with head injury following road traffic accident. Patients had mostly bony fractures without significant parenchyma injury. After a few days of trauma, both developed expressionless mask-like face with inability to close the eyes which was difficult to explain initially but later discovered to be due to bilateral FNP as a consequence of bilateral petrous temporal bone fractures. Typical facial asymmetry which is seen in unilateral facial palsy is absent in bilateral cases; hence, it is quite possible to miss the diagnosis initially.

\section{Case Description}

\section{Case 1}

A 40-year-old man presented with history of head trauma by a heavy vehicle (concrete mixer), followed by head hitting a wall which acted as a force of impact on the opposite side of his head. He was bleeding from right ear and vomiting. His Glasgow Coma Scale (GCS) was 15/15 (E4V5M6), pupils bilaterally symmetrical reacting to light, and no neurological deficits. He was already on treatment for type 2 diabetes mellitus, hypothyroidism, hypertension, and chronic renal disease, likely diabetic nephropathy. High-resolution thin cut computed tomography (CT) scan of skull revealed longitudinal fractures of right and left temporal bones (petromastoid) with associated sphenoid hemosinus, right inculomalleal dislocation, and extensive pneumocephalus with air in mesencephalic cisterns ( - Fig. 1). On
DOI https://doi.org/

10.1055/s-0039-1697999

ISSN 2277-954X. (c) 2020. Neurological Surgeons' Society of India.

This is an open access article published by Thieme under the terms of the Creative Commons Attribution-NonDerivative-NonCommercial-License, permitting copying and reproduction so long as the original work is given appropriate credit. Contents may not be used for commercial purposes, or adapted, remixed, transformed or built upon. (https://creativecommons.org/licenses/by-nc-nd/4.0/)

Thieme Medical and Scientific Publishers Pvt. Ltd., A-12, 2nd Floor, Sector 2, Noida-201301 UP, India 


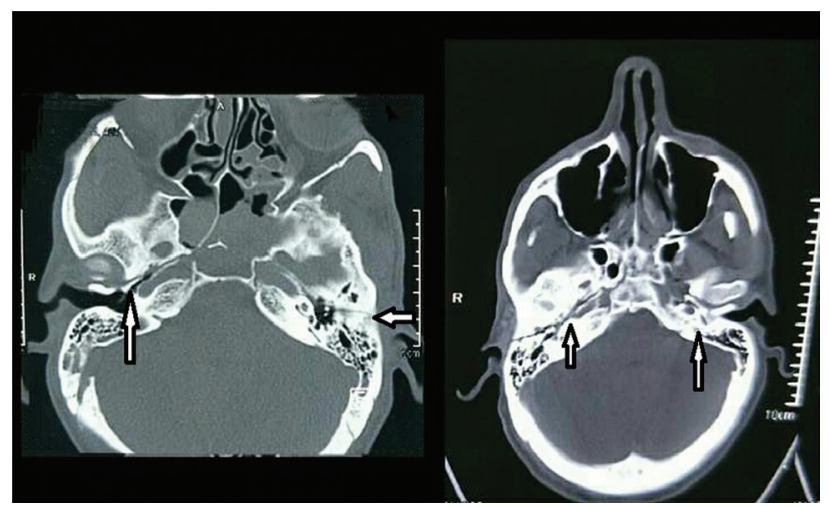

Fig. 1 Computed tomography scans of the brain of case 1 showing normal brain parenchyma but longitudinal fracture of the temporal bone.

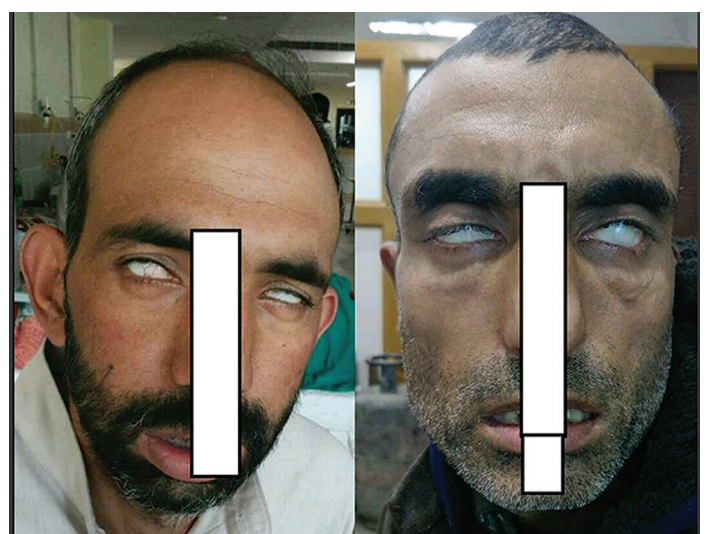

Fig. 2 Images of cases 1 and 2 showing incomplete eye closure, loss of nasolabial folds, and forehead wrinkling on both sides, and no characteristic deviation of angle of mouth with mask-like face.

the third day, he had difficulty while speaking, blowing air, and partial closure of eyelids (noticed by family). He had features of bilateral lower motor neuron facial palsy grade $\mathrm{V}$ (House and Brackmann [H\&B]). He was not able to frown, had incomplete eye closure, expressionless face, and loss of nasolabial folds (-Fig. 2). He had impaired lacrimation (both eyes) and taste disturbance in anterior two-thirds of the tongue. His hearing on left ear showed conductive deafness. Nerve conduction study of facial nerves revealed bilateral axonal neuropathy of the seventh cranial nerve. He was managed conservatively, and on discharge (9 days post injury) he still had facial weakness, H\&B grade V. After 3 weeks, he improved to grade IV. After 3 months, he was able to close both eyes and also chew his food properly and had improved to grade II (H\&B) score bilaterally.

\section{Case 2}

A 36-year-old man was admitted for head injury following fall from a bike. He was unconscious after the injury with a few episodes of vomiting and bilateral ear bleeding, but had no history of cerebrospinal fluid (CSF) otorrhoea or rhinorrhea. His GCS was 13 (E3 V4 M6), with pupils equal and reacting to light. He had incomplete closure of right eye, loss of nasolabial fold on right side, drooling of saliva, and deviation of mouth to left. After 12 hours, his GCS improved to score 15. On the third day, he was unable to close his eyes completely with up-rolling of eyeballs ( - Fig. 2) and unable to smile and frown, with characteristic mask-like face, difficulty in chewing, loss of taste, and persistent watering of eyes. He had bilateral FNP with H\&B grade V injury. Electroneronography (ENoG) confirmed bilateral facial nerve dysfunction. CT scan of brain revealed bilateral temporal bone (petromastoid) fracture with pneumocephalus and left temporal small extradural hematoma (EDH). On discharge, he had persistent features of bilateral facial palsy. On follow-up ( 6 weeks), there was appreciable improvement in his facial weakness more on the right side than left and after 3 months he had improved to $\mathrm{H} \& \mathrm{~B}$ grade II bilaterally.

\section{Discussion}

Only $5 \%$ of the FNPs are a result of head injuries, ${ }^{4,5}$ while others result from various medical conditions or idiopathic etiologies such as Bell's palsy. ${ }^{1}$ After olfactory nerve, facial nerve is the second most common cranial nerve involved in head injuries, albeit some recognize it as the most common nerve involved in head trauma. ${ }^{6,7}$ Simultaneous bilateral facial paralysis (SBFP) is an uncommon condition occurring in only 0.3 to $2 \%$ of cases presenting with facial palsy and is defined as "palsy affecting both sides of the face during a period less than 30 days." ${ }^{8}$ Usually bilateral facial palsy occurs in systemic diseases including Bell's palsy, sarcoidosis, Lyme disease, and Guillain-Barré syndrome and rarely head injury. ${ }^{9}$ Three percent of bilateral facial palsies are attributed to head injuries involving bilateral temporal bone fractures. ${ }^{4}$ Temporal bone fractures may be longitudinal $(90 \%)$ or transverse $(10 \%){ }^{4}$ Anatomically transverse fractures are perpendicular to external auditory canal and can stretch the genu and produce facial nerve dysfunction. Longitudinal fractures run through petrosquamous suture which is parallel to the external auditory meatus, sparing VIIth and VIIIth nerves, hence unlikely to cause facial palsy. Unilateral FNP is common following transverse temporal bone fractures (40-50\%) and longitudinal fractures contribute to less than $20 \%$ cases. ${ }^{10}$ But in our case, CT scan of the head showed longitudinal fractures of temporal bones bilaterally. De Villiers proposed that a longitudinal fracture of the petrous part of temporal bone can lead to backward displacement of the petrous apex and coronal splitting of the body of the sphenoid, leading to mirror image fracture in the opposite temporal bone producing bilateral FNP, while a transverse fracture of the petrous bone will not involve bilateral facial nerves. ${ }^{10}$ In our first case, the patient had no facial palsy on admission but developed bilateral facial palsy after the third day of trauma, which was unexpected initially. Delayed FNP can be explained by slowly increasing the size of hematoma into the facial canal or delayed edema causing compression of nerve within its fibrous sheath or epineurium. ${ }^{11}$ Diagnosis of traumatic bilateral facial palsy is a challenge owing to lack of characteristic facial asymmetry; hence, it warrants thorough cranial nerve examination, imaging, and electrodiagnostic tests. Electrodiagnostic studies such as electromyography (EMG) confirm the presence of demyelinating neuropathy affecting facial 
nerves and may also provide a clue to prognosis. High-resolution computed tomography (HRCT), especially with 1-mm thin cuts of the temporal bone, is a useful diagnostic tool for traumatic FNP; it can also define the direction of fracture line and degree of involvement of the fallopian canal.

The role of facial nerve decompression has always remained controversial; therefore, we followed the principle that ENoG and the clinical course of facial paralysis are the best guidelines. We prefer surgery only if patient is clinically deteriorating and/or shows 75 to $95 \%$ degeneration on serial ENoG within 2 weeks after the onset of facial palsy, to preserve the remaining axons.

Literature review reveals that surgery is not advisable beyond 2 weeks, because regeneration stage has already begun. ${ }^{11-13}$ Most cases are associated with concussion and edema of the nerve and may improve conservatively with steroids and physiotherapy. ${ }^{13}$ According to a study (Fisch et al) an early surgical intervention is warranted if ENoG indicates $90 \%$ amplitude reduction within 6 days post injury. ${ }^{14}$

\section{Conclusion}

Posttraumatic simultaneous bilateral facial palsy is a very rear entity. It may be difficult to diagnose due to the absence of the peculiar facial asymmetry but can be confirmed by detailed neurological examination along with electroneuronographic study of VIIth nerve and obtaining thin cuts $(1 \mathrm{~mm})$ of CT scan of the skull to identify the site and alignment of fracture lines. With timely identification and treatment, most patients are expected to show reasonable improvement.

\section{Conflict of Interest}

None declared.

\section{References}

1 Monnel K, Zachariah SB. Bell Palsy. http://emedicine.medscape. com/article/114903-overview.

2 Keane JR. Bilateral seventh nerve palsy: analysis of 43 cases and review of the literature. Neurology 1994;44(7):1198-1202

3 Teller DC, Murphy TP. Bilateral facial paralysis: a case prese ntation and literature review. J Otolaryngol 1992;21(1):44-47

4 Li J, Goldberg G, Munin MC, Wagner A, Zafonte R. Post-traumatic bilateral facial palsy: a case report and literature review. Brain Inj 2004;18(3):315-320

5 Steenerson RL. Bilateral facial paralysis. Am J Otol 1986;7(2): 99-103

6 Coello AF, Canals AG, Gonzalez JM, Martín JJ. Cranial nerve injury after minor head trauma. J Neurosurg 2010;113(3):547-555

7 Haberkamp TJ, Harvey SA, Daniels DL. The use of gadoliniumenhanced magnetic resonance imaging to determine lesion site in traumatic facial paralysis. Laryngoscope 1990;100(12): $1294-1300$

8 Stahl N, Ferit T. Recurrent bilateral peripheral facial palsy. J Laryngol Otol 1989;103(1):117-119

9 May M. The facial nerve palsy. Progressive facial nerve palsy: a management dilemma. Am J Otol 1990;11:458-460

10 De Villiers JC. Fracture-dislocation of the petrous temporal bone. J Neurol Neurosurg Psychiatry 1971;34:104-109

11 Sundar IV, Kurmi DV, Rao K, Sharma V, Chopra S, Jain SK. Delayed onset post-traumatic bilateral facial nerve paralysis: a rare case report. Indian Journal of Neurotrauma. 2012;9:143-146

12 Hanner P, Anderson O, Frisen L. Clinical observations of effects on CNS in patients with acute facial palsy. Arch Otolaryngol Head Neck Surg 1987;113:516-520

13 Hasso AN, Ledington JA. Traumatic injuries of the temporal bone. Otolaryngol Clin North Am 1988;21(2):295-316

14 Fisch U. Management of intratemporal facial nerve injuries. J Laryngol Otol 1980;94(1):129-134 